\title{
Participação, educação não escolar e problematização de práticas: uma perspectiva em elaboração
}

\section{Participation, non-school education and problematization of practices: a prospective in progress}

\author{
Luiza Helena Dalpiaz
}

\section{Resumo}

Neste trabalho, apresento elementos de uma abordagem exploratória da participação que venho realizando, desde dois pontos de vista distintos, cuja articulação se encontra em elaboração. Por um lado, trato da participação como constitutiva da noção de educação não escolar. A abordagem do tema é realizada por meio da orientação para elaboração de dissertações de mestrado; do levantamento da produção sobre o tema em periódicos qualificados, do campo da educação; de estudos exploratórios sobre indícios socio-históricos referentes à construção social do termo. A principal evidência é a característica híbrida e polissêmica da educação não escolar. Por outro lado, trabalho a participação como elemento estruturante de um método para problematização de práticas profissionais singulares, pelo qual problematizo políticas públicas. O objetivo é mostrar que a prática desse dispositivo de pesquisa-formação evidencia elementos pertinentes para o debate sobre a gestão democrática, em particular, sobre condições para a materialização desse princípio da política educacional na escola pública.

Palavras-chave: Análise institucional. Educação não escolar. Gestão democrática. Multirreferencialidade. Participação.

\section{Abstract}

In this work, I present elements of an exploratory approach that I have been conducting from participation, from two different points of view whose articulation is under development. On the one hand, I refer to participation as constituting the notion of non-school education. The approach of the subject is being carried out by means of the orientation for the elaboration of master's theses; The survey of production on the subject in qualified journals, in the field of education; Of exploratory studies on socio-historical evidences referring to the social construction of the term. The main evidence emerging from this work is the hybrid and polysemic characteristic of non-school education. On the other hand, I deal with participation as a structuring element of a method for problematization of singular professional practices, by which I problematize public policies. The objective is to show that the practice of this research-training device highlights pertinent elements to the debate on democratic management, in particular on the conditions for the materialization of this principle of educational policy in public school.

Keywords: Institutional analysis. Non-school education. Democratic management. Multi-referential. Participation.

\author{
Recebido em: 31/01/2017- Aprovado em: 08/05/2017 \\ http://dx.doi.org/10.5335/rep.v24i2.7414
}

\begin{abstract}
Doutora em Ciências da Educação pela Universidade Paris 8 Vincennes à Saint-Denis/França (Reconhecimento: UFSC). Professora-pesquisadora no Programa de Pós-Graduação em Educação da Universidade do Oeste de Santa Catarina (Unoesc). Líder do Grupo de Pesquisa Educação, Políticas Públicas e Cidadania (GEPPeC). E-mail: Ihdalpiaz@gmail.com
\end{abstract}




\section{Introdução}

O presente artigo é resultado de uma parceria acadêmica, tendo em vista minha entrada na equipe de pesquisadores da Universidade do Oeste de Santa Catarina (Unoesc), que está associada à Rede Mapa, ${ }^{1}$ pesquisa em rede que trabalha 0 tema da gestão democrática do ensino público. ${ }^{2}$ Conforme Nardi, como pressuposto da pesquisa se considera que "[...] a materialização do princípio constitucional da gestão democrática do ensino público (art. 206, inciso VI, da Constituição federal de 1988)" necessita "[...] condições de participação da sociedade civil nos processos decisórios acerca de assuntos de interesse comum", assim como "[...] das possibilidades concretas de a escola pública construir caminhos em um contexto de interdependência com o sistema de ensino ao qual se vincula" (2014, p. 4).

Em termos conjunturais, o Brasil pós-1988 se caracteriza por uma situação paradoxal em razão de exigências simultâneas e opostas: efetuar investimentos sociais e realizar ajustes estruturais, próprios ao ideário neoliberal (COUTO et al., 2010). Nesse contexto, o processo de institucionalização de políticas públicas evidencia uma trajetória fragmentada e contraditória. De um lado, constatam-se avanços e inovações na instalação de um aparato político-organizacional e na modernização do Estado; de outro, evidenciam-se entraves relativos à universalização, ao financiamento, à gestão e à qualidade de serviços prestados (ABRUCIO, 2007; LOBATO, 2009).

No campo das políticas educacionais, Nardi (2014) indica aspectos que mostram a discrepância entre o princípio constitucional democrático e a realidade da gestão escolar. Há uma ênfase persistente na função reivindicativa que limita práticas da participação ao objetivo do acesso ao direito; objetivo legítimo, porém insuficiente como parâmetro para embasar as funções legislativa e executiva da gestão pública municipal. Entretanto, nos sistemas de ensino locais, existem dificuldades, em diferentes planos, para que se construam e se estabeleçam normas e procedimentos próprios à gestão democrática, que explicitem formas e processos participativos, considerando atribuição abstrata prescrita pela Lei de Diretrizes e Bases da Educação Nacional (LDB), de 1996; tal protagonismo municipal é constitutivo da política de descentralização intrínseca ao modelo federativo brasileiro pós-1988.

Nardi (2014) também aponta para a institucionalização de espaços coletivos que potencialmente corporificam possibilidades concretas para o exercício de práticas participativas locais: estabelecimento de conselhos municipais, eleição de dirigentes escolares, realização de fóruns e conferências. No entanto, o autor sugere que tais possibilidades estão simultaneamente condicionadas pela tradição política 
patrimonialista e autoritária que particulariza a construção da sociedade brasileira (NARDI, 2015).

Segundo Paro, “[...] a participação da comunidade na escola, como todo processo democrático, é um caminho que se faz ao caminhar, o que não elimina a necessidade de se refletir previamente a respeito dos obstáculos e potencialidades que a realidade apresenta para a ação". E acrescenta o autor: "[...] a democracia só se efetiva por atos e relações que se dão no nível da realidade concreta" (2016, p. 24).

Nesse sentido, para Dourado, "[...] a análise da gestão educacional pode se realizar por meio de vários recortes e planos" (2007, p. 922). O autor enfatiza a necessidade da análise de concepções e das formas de gestão, "[...] importando, sobremaneira, apreendê-las no âmbito das relações sociais em que se forjam as condições para sua proposição e materialidade”. Dourado considera a educação como uma "[...] prática social, portanto, constitutiva e constituinte das relações sociais mais amplas, a partir de embates e processos em disputa que traduzem distintas concepções de homem, mundo e sociedade" (2007, p. 923).

Como pesquisadora na equipe da Rede Mapa, venho construindo uma contribuição para o debate coletivo, focalizado na gestão democrática, em particular, sobre condições para a materialização desse princípio da política educacional na escola pública. Minha perspectiva consiste em duas questões distintas, cuja articulação se encontra em elaboração: do ponto de vista temático, a abordagem da participação desde o problema da educação não escolar; do ponto de vista epistemológico e metodológico, a análise de políticas públicas a partir da problematização de práticas profissionais singulares, por meio de um método fundamentado em uma visão participativa.

O presente artigo está organizado em dois segmentos. No primeiro, apresento, brevemente, certos aspectos do percurso que levou a agregar o tema da educação não escolar ao meu programa de pesquisa e, depois, indico elementos do trabalho exploratório que estou realizando, junto com minha equipe (orientandos e pesquisadores associados), sobre o tema da educação não escolar. No segundo, exponho, de forma sucinta, referências conceituais e alguns resultados de pesquisas anteriormente realizadas que mostram particularidades de um caminho (método) para analisar políticas públicas, o qual é constituído de uma dimensão participativa.

\section{Educação não escolar: uma noção híbrida e polissêmica}

No meu trabalho, o tema da educação não escolar se situa na interface entre os campos do serviço social e da educação, em um longo percurso investigativo. $\mathrm{O}$ marco fundador se encontra na minha tese de doutorado em ciências da educa- 
ção, elaborada em contexto acadêmico francês. Nesse trabalho, formulei a noção de crise do praticante para analisar particularidades do mal-estar vivenciado pelo assistente social, em sua formação e prática profissionais, atravessadas por experiências de militância política.

A hipótese, então estabelecida, é a de que a superação da crise supõe que o praticante se torne praticante-pesquisador sobre sua própria prática para produzir conhecimentos. Em consequência, subsídios são assim gerados tendo em vista, potencialmente, contribuir para a (re)construção de projetos profissionais, organizacionais e científicos (DALPIAZ, 1994). ${ }^{3}$

No período 1995-2013/1, pesquisas realizadas nessa perspectiva e sob minha orientação, no serviço social, em diferentes contextos, produziram duas linhas investigativas distintas e entrelaçadas: formação de pesquisadores no serviço social (DALPIAZ, 2004, 2005) e educação permanente de operadores locais de políticas públicas (DALPIAZ, 2015).

No semestre 2013/2, o meu ingresso como docente-pesquisadora no Programa de Pós-Graduação em Educação (PPGEd) da Unoesc provocou a migração para o campo da educação. Em consequência, por razões de aderência institucional próprias à política nacional de pós-graduação, houve necessidade de (re)estabelecer e explicitar um eixo temático pertinente e instigante para orientar o rumo da pesquisa no novo campo de pertencimento.

Nesse caminho, o tema da educação permanente possibilitou construir um percurso orgânico, articulando investigações de cinco orientandos de mestrado, sobre temas próximos: educação social (VARGAS, 2015), educação integral (NUNES, 2016), formação do trabalhador (SIMÃO, 2016), assim como educação popular e a própria educação permanente, em duas dissertações ainda em elaboração.

Desse conjunto de trabalhos, a educação não escolar surge, então, como tema confluente. Do ponto de vista conceitual, Vargas (2015) constatou a dificuldade de estabelecer fronteiras entre diferentes termos que atravessam o vasto cenário da educação não escolar. Assim, associando diversos autores, estabeleceu uma distinção entre três termos, com a qual trabalhamos até o presente momento.

A educação escolar consiste na apropriação do conhecimento historicamente construído e sistematizado; essa forma educativa conta com legislação própria e prevê trajetórias sequenciais, em diferentes planos: da educação infantil ao ensino superior. A educação informal contempla, de forma permanente, as aprendizagens que constituem as experiências do indivíduo, ao longo de toda a vida.

A educação não escolar se particulariza pela combinação de duas dimensões simultâneas e indissociáveis, a intervenção e a intencionalidade, profissional e/ou militante, em diferentes contextos, na perspectiva do exercício da cidadania e do 
protagonismo das pessoas, para promover transformações individuais e coletivas. As formas interventivas se organizam tendo como base: o diálogo, a problematização da vida cotidiana e o processo participativo.

Lima (2007) mostra que a intervenção e a intencionalidade compõem um cenário contraditório e paradoxal, formado pela tensão entre duas tradições que são, constantemente, ressignificadas e reatualizadas no campo educativo: a raiz humanista e crítica e a raiz pragmática e conservadora.

A pesquisa de Vargas evidenciou que "[...] a desprofissionalização e a fragmentação" são problemas que afetam praticantes da educação não escolar, em consequência, produz-se "[...] a descontinuidade das políticas públicas" (2015, p. 98). Esse tipo de situação contém, implicitamente, demandas para a formação profissional de operadores locais vinculados a intervenções não escolares. A pesquisa de Nunes (2016) ampliou a abordagem desse problema emergente.

Nos semestres 2015/2 a 2016/2, uma mestranda realizou uma pesquisa exploratória para analisar características da abordagem da educação não escolar na produção científica do campo da educação. ${ }^{4}$ A metodologia utilizada foi o levantamento bibliográfico de artigos publicados em periódicos listados na base Qualis 2014 da Capes, disponíveis on-line, classificados como A1, A2, B1 e B2, os quatro estratos superiores da produção científica em periódicos. O período considerado foi entre os anos 2010 e 2015, referentes a dois triênios de avaliação da Capes.

A seleção de artigos considerou um critério amplo de inclusão: a abordagem da educação não escolar em diferentes formas e perspectivas, observando uma distinção da educação escolar. A coleta de dados se centrou nos resumos dos artigos. A análise de dados, realizada segundo pressupostos da análise de conteúdo, revelou, entre outros resultados: diversidade de áreas temáticas, variedade conceitual, multiplicidade de metodologias, heterogeneidade de atores sociais (DALPIAZ; PINHEIRO, 2016). ${ }^{5}$

Em síntese, duas hipóteses de trabalho se evidenciam. A primeira é a de que a educação não escolar se caracteriza por uma constituição híbrida e polissêmica, que associa diferentes, e mesmo opostas, tradições de pensamento e formas de práticas educativas. A segunda é a de que, no campo instituído de pesquisa em educação, tradicionalmente, a educação não escolar ocupa um lugar periférico em relação à questão central do campo: a educação escolar.

Do ponto de vista socio-histórico, em termos exploratórios e provisórios, diversas vertentes que se entrecruzam estão sendo examinadas para caracterizar cenários de emergência e particularidades da construção social da noção de educação não escolar. Para além de uma trajetória linear e determinista, assim como a título apenas indicativo de rumos/questões de pesquisas em andamento, destaco, 
a seguir, cinco indícios que, me parece, também revelam a constituição híbrida da educação não escolar. Tais pistas se referem a cinco formas educativas que se sobrepõem, seguidamente se confundem, por vezes se opõem, em referências bibliográficas e documentais com as quais temos trabalhado. ${ }^{6}$

Educação escolar. Para Afonso, a escola pública surge na modernidade "[...] incumbida da tarefa de ajudar a concretizar o projecto societal impulsionado pelos ideais da Revolução Francesa e da revolução industrial”. Em consequência dessa origem, a escola foi instituída para atender a dois objetivos: "[...] dar um contributivo decisivo para o progresso cultural, científico e técnico, e para a construção de percursos de emancipação pessoal e social que libertassem os indivíduos das amarras da ignorância e do obscurantismo" (2001, p. 29).

No entanto, o percurso da escola demonstra uma cisão histórica que foi sendo construída: indivíduos que ascenderam socialmente em contraposição a indivíduos "que ficaram pelo caminho". Em outros termos, a escola se caracterizou pela "[...] reprodução cultural consoante com os conhecimentos, interesses e valores dominantes, de indução classista de trajectórias de escolarização mais ou menos discriminatórias, e mesmo de legitimação de desigualdades e exclusões diversas" (AFONSO, 2001, p. 29).

Essas contradições levaram à crise da escola e à emergência, à valorização e ao desenvolvimento da educação não escolar como alternativa. No entanto, Afonso destaca: a "[...] educação não-escolar (informal e não-formal) sempre coexistiu com o campo da educação escolar, sendo mesmo possível imaginar sinergias pedagógicas muito produtivas e constatar experiências com intersecções e complementaridades várias" (2001, p. 31).

Educação popular. Maurel (2009, p. 5-6) considera que há três correntes de pensamento que marcam tanto a história quanto a atualidade da educação popular. Por um lado, o século das luzes e a Revolução Francesa, destacando a referência ao "Relatório Condorcet' sobre a Instrução pública de 1792", que propôs a criação dos sistemas educativos modernos. Por outro, o cristianismo social, sublinhando a influência da Encíclica Rerum Novarum (Papa Leão 13, 1891), “[...] que chamou os cristãos a se engajarem na questão operária”. E, ainda, o próprio movimento operário do século XIX, realçando a dimensão cultural "da luta e da ação coletiva".

Pedagogia social. A origem se situa na Alemanha, sociedade industrial em crise, entre final do século XIX e início do século XX. Nesse contexto, “[...] procurava-se na educação uma solução para os problemas humanos e sociais (fortes movimentos migratórios, proletarização do campesinato, desemprego, pobreza, exclusão econômica e cultural, abandono de menores, delinquência, entre outros)", em uma perspectiva comunitária (DÍAZ, 2006, p. 92-93). Segundo Díaz (2006), no 
contexto europeu, a pedagogia social é associada a intervenções socioeducativas de políticas sociais.

Educação de adultos. Em 1949, em Elsinore (Dinamarca), foi realizada pela Organização das Nações Unidas para a Educação, a Ciência e a Cultura (Unesco) a I Conferência Internacional de Educação de Adultos. "Após a devastação e horror da guerra, a educação de adultos foi vista como meio para consolidar a paz e estabelecer uma nova harmonia entre as nações e uma base para alargar o entendimento entre os povos até recentemente em guerra" (IRELAND, 2014, p. 32). Na III Conferência (1972, em Tóquio, Japão), o conceito de educação ao longo da vida adquiriu visibilidade internacional (IRELAND, 2014).

Educação permanente. Na XIX Conferência Geral da Unesco (1976, em Nairobi, Quênia), a expressão "educação permanente" foi definida como "[...] um projeto global que conduz tanto a reestruturar o sistema educativo existente, como a desenvolver todas as possibilidades de formação fora do sistema educativo"; nessa perspectiva, "[...] o homem é o agente de sua própria educação, por meio da interação permanente de suas ações e sua reflexão" (UNESCO, 1976, p. 2).

Nos anos 1960-1970, foi associada à educação permanente uma visão crítica baseada tanto no conceito de cidadania quanto na perspectiva freiriana da educação como prática da liberdade. Nos anos 1980, a educação permanente é condenada ao silêncio diante da crise do Estado de bem-estar, do surgimento de novos movimentos sociais e da crítica à visão universalista (OSÓRIO, 2005).

A partir dos anos 1990, a sociedade da informação (ou cognitiva ou de redes), as transformações e a crise do mundo do trabalho assim como a globalização provocaram o surgimento de novas necessidades e demandas. Essas levaram a reemergência da educação permanente no cenário coletivo, pois "[...] o saber se assume como principal produtor de riqueza e bem-estar" (OSÓRIO, 2005, p. 64). Conforme Osório (2005), desse contexto decorrem três tendências da educação permanente, vinculadas às perspectivas de três organismos internacionais.

Para o Banco Mundial, o conhecimento deve estar a serviço do desenvolvimento, ou seja, "[...] situa a reforma da educação como a dedução natural da reforma econômica neoliberal” (OSÓRIO, 2005, p. 48). Para a Organização para a Cooperação e Desenvolvimento Econômico (OCDE), a educação permanente "[...] está associada a motivações econômicas (instrumento de alta capacitação), mas também exige políticas ativas de emprego, coesão social, redistribuição da formação ao longo do ciclo vital, como necessidade de todas as pessoas" (OSÓRIO, 2005, p. 48). Já para a Unesco, "[...] a educação deve organizar-se em torno de quatro aprendizagens fundamentais que, ao longo de toda a vida, serão de algum modo para cada indivíduo, os pilares do conhecimento", ou seja, “[...] aprender a conhecer, 
aprender a fazer, aprender a viver juntos e aprender a ser" (DELORS et al., 1998, p. 89-90). Dessa forma, trata-se de articular trabalho, aprendizagem e cidadania ativa (DELORS et al., 1998).

Esse conjunto heterogêneo de dados entrecruzados está apontando para duas exigências no plano científico, considerando a condição híbrida e polissêmica da educação não escolar: por um lado, problematizar aspectos epistemológicos e teóricos, assim como metodológicos e políticos, por outro, de forma complementar, estabelecer peculiaridades da intervenção educativa não escolar e, em decorrência, explicitar possibilidades e efeitos, em diferentes instâncias, que lhe são próprios.

No próximo segmento do presente artigo, exponho, sucintamente, referências conceituais e alguns resultados de pesquisas anteriormente realizadas que mostram particularidades de um método para analisar práticas profissionais singulares, o qual é constituído de uma dimensão participativa. Esse trabalho contém elementos da visão e da via pelas quais tenho (re)construído caminhos, individuais e coletivos, para problematizar a educação não escolar. Ao mesmo tempo, essa perspectiva contém subsídios que, potencialmente, poderão fomentar o debate na Rede Mapa, focalizado na gestão democrática, em particular, sobre condições para a materialização desse princípio da política educacional na escola pública.

\section{Problematização de práticas profissionais singulares}

Método significa caminho, que se inspira em princípios a operacionalizar, e não se reduz a procedimentos formais e/ou preestabelecidos, a reproduzir ou a repetir. O método refere-se a um conjunto de ideias que estabelecem uma perspectiva e certas condições estratégicas, considerando-se a realização de um percurso para a produção de conhecimentos (MORIN, 1986). No plano teórico, o método aqui abordado tem como base uma tríade de referências indissociáveis.

A multirreferencialidade considera a hipótese da complexidade da realidade e propõe uma leitura plural do problema/objeto de investigação, considerando pontos de vista distintos e heterogêneos. Esse trabalho exige cuidado e rigor epistemológicos para delimitação e articulação de diferentes saberes e conhecimentos, pertinentes e significativos, considerando características próprias do problema/ objeto em pauta (ARDOINO, 1993).

A análise institucional socioanalítica indaga relações de poder e relações com o saber. A "análise em situação" trata de "[...] decifrar as relações que os indivíduos e os grupos mantêm com as instituições" (LOURAU, 1970, p. 267). Nesse sentido, provoca a emergência do não saber (o invisível, o não dito, o oculto, o escotoma, o inconsciente) de sujeitos implicados na situação analisada (AUTHIER; HESS, 1981). 
O modelo de múltiplas trajetórias para avaliação de políticas sociais coloca em relação fatos e discursos, traçando trajetórias de diferentes atores presentes, em diversos planos, no tecido social da prática considerada. Esse modelo supõe a construção de dispositivos de pesquisa-formação, a serem instituídos por meio de práticas participativas que promovam a parceria entre pesquisadores e praticantes, para produzir conhecimentos (ZECCA, 1989).

Um ponto de convergência dessa tríade de referências consiste na perspectiva da produção de uma ruptura epistemológica, condicionada à mudança de lugar do sujeito que produz conhecimentos: o sujeito, individual e/ou coletivo, tradicionalmente dissociado do problema/objeto que investiga, passa a problematizar sua prática profissional, reconhecendo-se implicado na trama social que interroga.

Em toda prática, o sujeito está situado em um "nó de relações". Em termos institucionalistas, o sujeito que analisa sua implicação considera a interação, a relação e a ação recíproca, entre sujeito-objeto-situação (LOURAU, 1990). Essa análise exige um trabalho paradoxal, entre forças simultâneas e contrárias: aproximação-distanciamento do sujeito, delimitação-complexificação do problema/ objeto e subjetivação-objetivação dos conhecimentos.

Para articular elementos da tríade teórica de referência, trabalho com duas noções operativas - crise do praticante e tensão paradigmática. Dessa forma, criam-se condições que estabelecem, ao mesmo tempo, um princípio organizador do pensamento e um "ponto de partida" singular, no qual o sujeito inicia seu processo para produção de conhecimentos.

No sentido etimológico, o termo grego krisis significa decisão. Em situações em que há certezas e garantias, a crise instaura dúvidas, imprevisibilidade, e abre um campo de possibilidades, com diferentes tendências: de transgressão e mudança; de (re)acomodação e retorno ao status quo; ou de agravamento da situação inicial. A noção de praticante refere-se ao sujeito que exerce sua prática, em diferentes campos de intervenção (social, educativo, político, terapêutico, científico, etc.), em distintas instâncias organizacionais e institucionais.

A crise do praticante é constituída por três elementos entrecruzados e interdependentes: existencial (problemas de identidade profissional, individual e coletiva); político (dificuldades com relações de poder e nas relações com o saber) e científico (conflitos entre teoria e prática). A hipótese, então formulada, é a de que a superação da crise supõe que o praticante se torne praticante-pesquisador sobre sua própria prática para produzir conhecimentos e, assim, gerar subsídios para a (re)construção do projeto visado do sujeito (DALPIAZ, 1994).

O praticante, ao se interrogar sobre sua própria prática, opera o princípio holográfico da complexidade: “[...] o todo está na parte que está no todo" (MORIN, 
1986, p. 101). Esse princípio supõe que a pergunta do sujeito singular expressa um problema do respectivo campo de referência. A questão do sujeito caracteriza-se, ao mesmo tempo, como um indício, que sinaliza sentidos implícitos da prática (GINZBURG, 1989), e, em termos institucionalistas, como um analisador, pois permite “[...] revelar a estrutura da instituição, provocá-la, forçá-la a falar" (LOURAU, 1970, p. 283).

O trabalho para formulação da pergunta singular produz uma tensão paradigmática, ao desvelar a concomitância e o conflito entre tradições e exigências distintas - profissionais, políticas e científicas - que constituem o sujeito em sua prática (DALPIAZ; DE LA FARE, 2000). A prática é considerada um tecido composto de elementos indissociáveis, múltiplos e heterogêneos, em interação, que produzem formas sociais, que se fazem e se desfazem sem parar, em um processo contínuo de institucionalização, no tensionamento entre forças instituídas e instituintes (DALPIAZ, 2002).

As duas noções operativas, crise do praticante e tensão paradigmática, particularizam o método para problematização de práticas profissionais. Esse método instaura condições para questionar percursos e situações, possibilitando, simultaneamente, a emergência da pergunta do sujeito que produz conhecimentos. Em consequência, subsídios são gerados tendo em vista, potencialmente, contribuir para a (re)construção de projetos profissionais, organizacionais e científicos (DALPIAZ, 2015).

Esse método tem sido transposto em diferentes dispositivos formativos, para a formação tanto de pesquisadores (pesquisa) quanto de praticantes (ensino, extensão, cursos de curta duração, assessorias). Neste trabalho, a participação se constitui como um dos fundamentos. Meu objetivo é mostrar que a prática desse dispositivo de pesquisa-formação evidencia elementos pertinentes para o debate sobre a gestão democrática, em particular, sobre condições para a materialização desse princípio da política educacional na escola pública.

$\mathrm{Na}$ sequência, apresento, de forma resumida, quatro elementos metodológicos que, entre outros, caracterizam este trabalho. Tais elementos têm marcas próprias, entrecruzam-se e influenciam-se mutuamente, assim como são partes de um todo, articulado e orgânico, continuamente aberto ao devir.

A construção de parcerias interinstitucionais, internas e/ou externas, visando associar praticantes e pesquisadores para a produção de conhecimentos, supõe um trabalho exigente e contínuo de articulação sociopolítica; logo, não se reduz a cerimônias e/ou a documentos protocolares, em geral, também necessários e compreensíveis. Trabalhar em parceria requer divulgação e circulação de informações entre diferentes interlocutores para que ocorra cooperação. Além disso, presume 
explicitação e negociação de pontos de vista diversos, não raras vezes contrários, para que se estabeleçam zonas nas quais haja reconhecimento mútuo e convergências, as quais não se confundam com consensos. Tais condições parecem viabilizar a construção de ações compartilhadas entre sujeitos estruturalmente distintos. Esse tipo de prática contém um problema transversal: a relação simbólica entre membros de unidades sociais binárias (praticantes e pesquisadores, técnicos e gestores, etc.), nas quais frequentemente se reproduzem hierarquias implícitas e desqualificações mútuas.

O lugar institucional do praticante, entre outras particularidades, comumente, caracteriza-se pelo cotidiano tarefeiro e ativista, pelo excesso de exigências contraditórias em precárias condições de trabalho, pela violência em diferentes planos. Como contraponto, nesse contexto, verifica-se a demanda para a institucionalização de um espaço-tempo regular e sistemático, específico para prosseguir estudos e realizar pesquisas, a ser, necessariamente, considerado como parte da agenda, sempre transbordante, individual e organizacional. Experiências realizadas indicam que esse tipo de espaço-tempo estabelece fronteiras simbólicas e materiais, instituindo um território peculiar que favorece o trabalho reflexivo. Também se observa como possível, então, instaurar acordos coletivos que contribuam para o estabelecimento de um ambiente de escuta e de autorização, no qual se exercitem expressão individual, não julgamento do outro, reflexão compartilhada e debate de ideias. Dessa forma, esse contexto provoca a emergência de necessidades de conhecimento, imperativos de protagonismo e desejos de autoria. Simultaneamente, promove a experiência, sempre perturbadora e nunca finalizada, com a desconstrução de posturas autoritárias, visões deterministas, pensamentos monorreferenciais.

Outro procedimento se refere ao agenciamento, no dispositivo formativo, de uma base sociopolítica constituída por um conjunto de unidades: os grupos de trabalho (GTs). Cada GT é formado, prioritariamente, por quatro membros e organizado pelo princípio da heterogeneidade de pertencimentos dos participantes. Os GTs articulam as outras duas unidades presentes na cena pública do dispositivo: cada indivíduo e o coletivo. Nesses termos, os GTs compõem uma trama e um microambiente experiencial em que se reproduzem, entre outras situações, contradições e dificuldades próprias à vida na sociedade, à inserção nas organizações e nas comunidades, ao trabalho em equipe. Tais tensões emergem e são (re)trabalhadas a partir, e em função, de tarefas propostas a realizar, considerando a construção de uma ação compartilhada. $\mathrm{O}$ trabalho com os GTs se diferencia de outras propostas metodológicas que priorizam abordagens focadas nas relações interpessoais.

A análise de situações singulares de intervenção consiste no procedimento pelo qual o praticante adentra na complexidade da prática em uma perspectiva delimi- 
tada e densa. Cada sujeito (um indivíduo, um grupo ou uma equipe, dependendo do tipo de dispositivo formativo) seleciona uma situação na qual esteja diretamente implicado na intervenção (realizada, em andamento ou a projetar). $\mathrm{O}$ critério de escolha é tratar-se de uma situação sobre a qual o praticante se interrogue, em qualquer plano que julgue pertinente investigar. A situação eleita servirá de guia e orientará o trabalho para a produção de conhecimentos. O detalhamento desse trabalho requer um desenvolvimento que ultrapassa o limite do presente artigo. ${ }^{7}$

\section{Considerações finais}

O trabalho realizado no contexto da Rede Mapa é centrado na gestão democrática, em particular, sobre condições para a materialização desse princípio da política educacional na escola pública. Essa materialização implica que se estabeleçam condições para a institucionalização de práticas participativas. No contexto do Brasil pós-1988, a institucionalização de políticas públicas apresenta uma trajetória fragmentada e contraditória, feita de avanços e de entraves.

Autores que são referência no campo da educação mostram posições que convergem para o reconhecimento da democracia como uma prática social. Tendo em vista que se trata de construção permanente, a democracia implica tanto a análise de concepções e formas da sociedade quanto a reflexão sobre obstáculos e potencialidades da realidade.

No trabalho que realizo com a equipe de pesquisadores da Rede Mapa, minha contribuição para o debate coletivo se situa entre duas questões distintas, cuja articulação se encontra em elaboração. Do ponto de vista temático, a abordagem da participação desde o problema da educação não escolar; do ponto de vista epistemológico e metodológico, a análise de políticas públicas a partir da problematização de práticas profissionais singulares, por meio de um método fundamentado em uma visão participativa.

Para abordar a educação não escolar, organizo e coordeno uma equipe de orientandos e pesquisadores associados com os quais tenho realizado caminhos complementares para a produção de conhecimentos: orientação para elaboração de dissertações de mestrado; levantamento da produção sobre o tema em periódicos qualificados, do campo da educação; estudos exploratórios sobre indícios socio-históricos referentes à construção social da educação não escolar.

A principal evidência que emerge desse trabalho, até o momento da escrita deste texto, é a característica híbrida e polissêmica da educação não escolar. Em consequência, por um lado, impõe-se problematizar aspectos epistemológicos e teóricos, assim como metodológicos e políticos; por outro, de forma complementar, 
verifica-se a necessidade de estabelecer peculiaridades da intervenção educativa não escolar e, em decorrência, explicitar, em diferentes instâncias, possibilidades e efeitos que lhe são próprios.

Em termos conceituais, a educação não escolar implica intervenção e intencionalidade, profissional e/ou militante, em diversos contextos, na perspectiva do exercício da cidadania e do protagonismo das pessoas, para promover transformações individuais e coletivas. As formas interventivas se organizam tendo como base: o diálogo, a problematização da vida cotidiana e o processo participativo. Logo, a participação é constitutiva da educação não escolar.

A análise de políticas públicas a partir da problematização de práticas profissionais singulares implica o trabalho com um método construído a partir de uma tríade de referências conceituais. Elementos dessa tríade são articulados a partir de duas noções operativas: crise do praticante e tensão paradigmática. Esse método é constituído de uma dimensão participativa.

Então, apresentei e analisei, de forma resumida, quatro elementos metodológicos que, entre outros, caracterizam esse trabalho: a construção de parcerias interinstitucionais entre praticantes e pesquisadores para construir conhecimentos; a institucionalização de um espaço-tempo regular e sistemático para prosseguir estudos e realizar pesquisas, favorecendo o trabalho reflexivo; o agenciamento de uma base sociopolítica, organizada pelo princípio da heterogeneidade de pertencimentos dos participantes; a análise de situações singulares de intervenção.

Conforme procurei explicitar desde o início do texto, o trabalho que apresento encontra-se em elaboração. Em consequência, para além de um conjunto complexo de dados exploratórios e de análises preliminares, a relação da participação com a educação não escolar e a problematização de práticas se mostra um caminho estimulante e provocativo de pesquisa.

Tendo em vista os contornos temáticos e o foco do presente artigo, minha abordagem exploratória da participação não contemplou, até o momento, novas formas de cidadania que ocupam a cena pública. Um autor como Castells (2013) indica, a meu ver, inelutável complemento a considerar na sequência da pesquisa, tendo em vista a modificação radical que a internet provoca no laço social contemporâneo.

\section{Notas}

1 Gestão democrática do ensino público: mapeamento das bases normativas e das condições político-institucionais dos sistemas municipais de ensino. O Coordenador da pesquisa é o professor doutor Elton Luiz Nardi (PPGEd/Unoesc). A pesquisa envolve pesquisadores, responsáveis por respectivos subprojetos estaduais, das seguintes instituições: Universidade do Oeste de Santa Catarina (Unoesc), Universidade de Passo Fundo (UPF), Universidade Federal de Santa Maria (UFSM), Universidade Estadual do Rio de Janeiro (UERJ), Universidade Estácio de Sá (Unesa), Universidade Federal do Maranhão (UFMA), Universidade Federal do Ceará (UFC), Universidade Federal do Tocantins (UFT) e Universidade Estadual 
do Piauí (Uespi). Os financiadores são: Conselho Nacional de Desenvolvimento Científico e Tecnológico (CNPq), Fundação de Amparo à Pesquisa e Inovação do Estado de Santa Catarina (Fapesc), Secretaria de Educação do Estado de Santa Catarina e Unoesc.

2 O objetivo de pesquisa é "[...] analisar o quadro normativo e as condições político-institucionais relativos à gestão democrática do ensino público, no âmbito dos sistemas municipais de ensino dos estados participantes da Rede Mapa, tendo em vista a atribuição que lhes foi conferida pela atual Lei de Diretrizes e Bases da Educação Nacional (Art. 14) quanto à definição de normas de gestão democrática na educação básica, de acordo com suas peculiaridades" (NARDI, 2014, p. 4).

3 No próximo segmento, apresentarei elementos da base conceitual que fundamenta esse trabalho.

4 Pesquisa financiada pelo Fundo de Apoio à Pesquisa (Fape) da Unoesc.

5 Manuscrito sobre essa pesquisa está em fase final de elaboração e será, em breve, submetido a periódico qualificado.

6 Além das cinco formas referidas, estudos realizados mostram que há outros termos a serem considerados, em tal cenário complexo: educação integral, educação social, educação continuada, educação comunitária, educação ao longo da vida, animação cultural, formação por competências.

7 Para conhecimento mais detalhado, ver Dalpiaz (2015).

\section{Referências}

ABRUCIO, F. L. Trajetória recente da gestão pública brasileira: um balanço crítico e a renovação da agenda de reformas. Revista Administração Pública, Rio de Janeiro, v. 41, ed. especial, p. 67-86, 2007. Disponível em: <http://www.scielo.br/scielo. php?script=sci_arttext\&pid=S0034$-76122007000700005 \& l n g=e n \& n r m=i s o>$. Acesso em: 3 maio 2014.

AFONSO, A. J. Os lugares da educação. In: VON SIMSON, O. R. de M.; PARK, M. B.; FERNANDES, R. S. (Org.). Educação não formal: cenários da criação. Campinas, SP: Unicamp/Centro de Memória, 2001. p. 29-38.

ARDOINO, J. L'approche multiréférencielle (plurielle) des situations éducatives et formatives. Pratiques de Formation - Analyses, Saint-Denis, n. 25-26, p. 15-41, abr. 1993.

AUTHIER, A.; HESS, R. L’analyse institutionnelle. Paris: 1981. (Que sais-je?, 1968).

CASTELLS, M. Redes de indignação e esperança: movimentos sociais na era da internet. Tradução de Carlos Alberto Medeiros. Rio de Janeiro: Zahar, 2013.

COUTO, B. R. et al. (Org.). O Sistema Único de Assistência Social no Brasil: uma realidade em movimento. São Paulo: Cortez, 2010.

DALPIAZ, L. H. Devenir praticien-chercheur, une possibilité pour le dépassement de la crise des travailleurs sociaux: l'approche d'une assistante sociale. 1994. Thèse (Doctorat en Sciences de l'Éducation) - Département des Sciences de l'Éducation, Université Paris VIII - Vincennes à Saint-Denis, Saint-Denis-France, 1994.

Educação permanente e políticas públicas: problematização de práticas e produção de conhecimentos. Roteiro, Joaçaba, v.40, ed. especial, p. 173-192, 2015. Disponível em: <http://editora.unoesc.edu.br/index.php/roteiro/article/view/9189/5248>. Acesso em: 5 jan. 2016.

. Formação de pesquisadores e prática de orientação no Serviço Social. In: ENCONTRO NACIONAL DE PESQUISADORES EM SERVIÇO SOCIAL, 8, 2002, Juiz de Fora. Anais... Juiz de Fora: ABEPSS, 2002. 1 CD-ROM. 
Método de problematização de práticas sociais e formação profissional. Revista Temas Sociais em Expressão, Frederico Westphalen, v. 4, n. 4, p. 67-82, maio 2005.

DALPIAZ, L. H.; DE LA FARE, M. A pesquisa como problema: elementos de um método de pesquisa-formação no Serviço Social. In: ENCONTRO NACIONAL DE PESQUISADORES EM SERVIÇO SOCIAL - "O serviço social e a questão social: direitos e cidadania", 7, 2000, Brasília, DF. Anais... Brasília, DF: ABEPSS, 2000.

DALPIAZ, L. H.; PINHEIRO, J. F. A. Elementos da pesquisa sobre a educação não escolar no campo da educação. In: SEMINÁRIO DE INICIAÇÃO CIENTÍFICA, 22; SEMINÁRIO INTEGRADO DE ENSINO, PESQUISA E EXTENSÃO, 9; MOSTRA UNIVERSITÁRIA, 7, 2016, Joaçaba, SC. Anais... Joaçaba, SC: Unoesc, 2016.

DELORS, J. et al. Educação um tesouro a descobrir: relatório para a Unesco da Comissão Internacional sobre Educação para o século XXI. São Paulo: Cortez; Brasília, DF: Unesco, 1998.

DÍAZ, A. S. Uma aproximação à pedagogia - educação social. Revista Lusófona de Educação, Lisboa, n. 7, p. 91-104, 2006. Disponível em: <http://revistas.ulusofona.pt/index.php/rleducacao/ issue/view/64> Acesso em: 11 abr. 2015.

DOURADO, L. F. Políticas e gestão da educação básica do Brasil: limites e perspectivas. Educação \& Sociedade, Campinas, v. 28, n. 100 - Especial, p. 921-946, out. 2007. Disponível em <http:// www.cedes.unicamp.br>. Acesso em: 17 abr. 2017.

IRELAND, T. D. Sessenta anos de CONFINTEAs: uma retrospectiva. In: IRELAND, T. D.; SPEZIA, C. H. (Org.). Educação de adultos em retrospectiva: 60 anos de CONFINTEA. Brasília: Unesco; Ministério da Educação, 2014. p. 30-56. Disponível em: <http://unesdoc.unesco.org/ images/0023/002305/230540POR.pdf>. Acesso em: 16 abr. 2015.

GINZBURG, C. Mitos, emblemas, sinais: morfologia e história. Tradução de Federico Carotti. São Paulo: Companhia das Letras, 1989.

LIMA, L. C. Educação ao longo da vida: entre a mão direita e a mão esquerda de Miró. São Paulo: Cortez, 2007.

LOBATO, L. de V. C. Dilemas da institucionalização de políticas sociais em vinte anos da Constituição de 1988. Ciência Saúde Coletiva, Rio de Janeiro, v. 14, n. 3, p. 721-730, jun. 2009. Disponível em: <http://www.scielo.br/scielo.php?script=sci_arttext\&pid=S1413-81232009000300008\&ln $\mathrm{g}=\mathrm{en \& nrm}=\mathrm{iso}>$. Acesso em: 3 maio 2014.

LOURAU, R. Implication et surimplication. Revue du Mauss, Paris, n. 10, p. 110-120, 4. trim. 1990.

. L'analyse institutionnelle. Paris: Minuit, 1970. (Arguments)

MAUREL, C. Avant-propos. Vie Sociale - “Éducation populaire: disparition ou mutation?”, Paris, n. 4, p. 5-6, 2009. Disponível em: <http://www.cedias.org/sites/cedias.org/files/avant-propos_ vs_4-2009.pdf>. Acesso em: 17 fev. 2017.

MORIN, E. La méthode: 3. La connaisance de la conaissance. Paris: Seuil, 1986. (Points, Essais).

NARDI, E. L. Gestão democrática do ensino público: mapeamento das bases normativas e das condições político-institucionais dos sistemas municipais de ensino. Joaçaba, SC: Unoesc, 2014. Projeto de pesquisa. 
Itinerários da participação na gestão de escolas públicas de educação básica. Revista Brasileira de Política e Administração da Educação, Porto Alegre, v. 31, n. 3, p. 649-666, set./ dez. 2015. Disponível em: <http://seer.ufrgs.br/index.php/rbpae/article/view/59089>. Acesso em: 17 abr. 2017.

NUNES, P. R. R. Políticas de educação integral: mudanças, contradições, (des)continuidades produzidas na escola pública básica. 2016. Dissertação (Mestrado em Educação) - Programa de Pós-Graduação em Educação, Universidade do Oeste de Santa Catarina, Joaçaba, SC, 2016.

PARO, V. H. Gestão democrática da escola pública. 4. ed. rev. e atual. São Paulo: Cortez, 2016.

OSÓRIO, A. R. Educação permanente e educação de adultos. Tradução Isabel Andrade. Lisboa: Instituto Piaget, 2005. (Horizontes Pedagógicos)

UNESCO. Recomendación relativa al desarrollo de la educación de adultos: aprobada por la por la Conferencia General en su decimonovena reunión. Nairobi: Unesco, 26 de noviembre de 1976. Disponível em: <http://www.unesco.org/education/pdf/NAIROB_S.PDF>. Acesso em: 6 mar. 2017.

VARGAS, S. R. S. de. Educação não escolar e política de segurança pública: tensões emergentes. 2015. Dissertação (Mestrado em Educação) - Programa de Pós-Graduação em Educação, Universidade do Oeste de Santa Catarina, Joaçaba, SC, 2015.

SIMÃO, A. A. Transformações do mundo do trabalho: o sujeito aprendente. 2016. Dissertação (Mestrado em Educação) - Programa de Pós-Graduação em Educação, Universidade do Oeste de Santa Catarina, Joaçaba, SC, 2016.

ZECCA, M. L'évaluation: outils d'émancipation? In: BACHMANN, C. Les savoirs-faire de l'inquiètude et du renouveau: une formation à l'évaluation de l'action sociale. Paris: PROMOFAF, 1989. p.57-59. 